\title{
Induced pluripotency and direct reprogramming: a new window for treatment of neurodegenerative diseases
}

\author{
Rui Li, Ye Bai, Tongtong Liu, Xiaoqun Wang ${ }^{\bowtie}$, Qian Wu ${ }^{\bowtie}$ \\ State Key Laboratory of Brain and Cognitive Science, Institute of Biophysics, Chinese Academy of Sciences, Beijing 100101, \\ China \\ $\triangle$ Correspondence: qianwu@moon.ibp.ac.cn (Q.Wu), xiaoqunwang@ibp.ac.cn (X. Wang) \\ Received August 26, 2012 Accepted January 9, 2013
}

\begin{abstract}
Human embryonic stem cells (hESCs) are pluripotent cells that have the ability of unlimited self-renewal and can be differentiated into different cell lineages, including neural stem (NS) cells. Diverse regulatory signaling pathways of neural stem cells differentiation have been discovered, and this will be of great benefit to uncover the mechanisms of neuronal differentiation in vivo and in vitro. However, the limitations of hESCs resource along with the religious and ethical concerns impede the progress of ESCs application. Therefore, the induced pluripotent stem cells (iPSCs) via somatic cell reprogramming have opened up another new territory for regenerative medicine. iPSCs now can be derived from a number of lineages of cells, and are able to differentiate into certain cell types, including neurons. Patient-specific iPSCs are being used in human neurodegenerative disease modeling and drug screening. Furthermore, with the development of somatic direct reprogramming or lineage reprogramming technique, a more effective approach for regenerative medicine could become a complement for iPSCs.
\end{abstract}

KEYWORDS human embryonic stem cells (hESCs), neuronal differentiation, induced pluripotent stem cells (iPSCs), somatic direct reprogramming, lineage reprogramming, regenerative medicine

\section{INTRODUCTION}

Neurodegenerative diseases are characterized by the chronic and progressive structure or function loss of neurons, including death of neurons, which results in memory deficits, cognitive deterioration, and impaired motor coordination. Many neurodegenerative diseases such as Parkinson's disease (PD), Alzheimer's disease (AD), Huntington's disease (HD), Spinal Muscular Atrophy (SMA) and Amyotrophic Lateral Sclerosis (ALS) occur as a result of neurodegenerative processes. To date, although there is no known effective treatment for these neurodegenerative diseases, therapies by using stem cells have been presented as a potential cell replacement approach to treat these diseases by supplementing the progressive loss of neuron. A primary concept of regenerative medicine is producing new cells to repair or replace diseased and/or damaged tissues. Currently, many innovative advances have been reported in cell differentiation. For example, pluripotent ESCs differentiate directly into distinct classes of neural cells (Zhang, 2006; Dhara and Stice, 2008; Elkabetz and Studer, 2008; Gaspard and Vanderhaeghen, 2010), patient-derived iPSCs have been utilized in the development of disease-specific cellular modeling and drug screening (Park et al., 2008; Boulting et al., 2011), and direct lineage reprogramming can yield a variety of subtype-specific neurons, which would be invaluable for cell therapies for different neurological diseases (Vierbuchen et al., 2010; Son et al., 2011). Here we will discuss the recent studies of ESCs and iPSCs and their potential future applications in regenerative therapeutics.

\section{EMBRYONIC STEM CELLS (ESCs) DIFFERENTIATE INTO NEURONS}

Derived from an early embryo, namely blastocyst, human embryonic stem cells (hESCs) are pluripotent cells that have the capacity of unlimited self-renewal proliferation (Thomson, 1998) and the ability to differentiate into multiple cell lineages (Evans and Kaufman, 1981), including neural stem (NS) cells. 
NS cells generate the main components of the nervous system whose development starts at the earliest stage of embryogenesis. Exploration of NS cells has been an essential and inspirational task for neuroscientists since Altman and Das' discovery of newly formed neurons in 1965 (Altman and Das, 1965). NS cells, acquiring the defining features of ESCs of pluripotency, are able to differentiate into major central nervous system (CNS) lineages, including oligodendrocytes, astrocytes and neurons, with their unique patterns of cell proliferation and differentiation. Neural differentiation of ESCs consists of three progressive steps, including neural induction, expansion and maintenance of NS cells, and differentiation into neurons and glias (Denham and Dottori, 2009). Nowadays, researches mainly focus on NS cells in the subgranular zone (SGZ) of the hippocampus as well as the subventricular zone (SVZ) of the forebrain which are two major niches in adult brain (Yao et al., 2012). The neural differentiation of ESCs in vivo is highly regulated by intrinsic signaling system consisting of plenty of morphogens (signaling molecules) and transcription factors, and the external microenviroment where secretions from ambient cells. In addition, epigenetic regulation also plays an essential role in ESCs neural differentiation.

\section{Morphogens}

Morphogens are signaling molecules that act directly on cells to induce distinct cellular response by forming a concentration gradient when spreading in the tissue from their source (Tabata and Takei, 2004), including bone morphogenetic proteins (BMPs), sonic hedgehog (Shh), and wingless-type MMTV integration site family (Wnt). They can work independently, or interweave to perform complicated regulations (Dhara and Stice, 2008).

Bone morphogenetic proteins, belong to transforming growth factor $\beta$ (TGF $\beta$ ) superfamily, regulating cell fate decisions in stem cells (Varga and Wrana, 2005). They are pivotal morphogenic signals that orchestrate tissue architecture in the body. BMP signaling prevents oligo-glial differentiation, but promotes neuronal and astro-glial cell generation. Ligand binds to the heterotetrameric complexes of type II and type I receptors in the BMP pathway, leading to phosphorylation of receptorregulated Smads 1, 5, and 8 which in turn bind to Smad 4 (Denham and Dottori, 2009). These complex accumulate in the nucleus to regulate transcription (Attisano and Wrana, 2002). In somatic cell reprogramming, BMPs are found to be able to functionally replace Klf4, which mainly plays a role in initiating mesenchymal-to-epithelial transition in cell reprogramming. In addition, BMPs are shown to boost the efficiency of other factor-mediated reprogramming of mouse embryonic fibroblasts (MEFs) to about 1\% (Chen et al., 2011).

Sonic hedgehog is an instrumental factor in regulating early embryo development. It has been suggested as a key inductive signal in patterning of the ventral neural tube (Dessaud et al., 2008), the anterior-posterior limb axis (Wang et al., 2000), and the ventral somites (Marti et al., 1995). The N-terminal portion of Shh is soluble which activates the signaling pathway while the C-terminal portion is involved in precursor processing as well as restricting the $\mathrm{N}$-terminal product to the cell surface, therefore it prevents Shh from freely diffusing in the developing embryo by covalently attaching a cholesterol moiety to the $\mathrm{N}$ terminal product. Shh is a dopaminergic neuron differentiation factor, and it has a downstream transcription factor target Gli-1 (Lee et al., 1997). Defects of Shh or deficiency of Shh signaling pathway may cause holoprosencephaly (HPE) (Mullor et al., 2002), a disorder in which the developing forebrain are not able to separate into right and left hemispheres properly, and may be responsible for VACTERL syndrome (Kim et al., 2001). The wingless-type MMTV integration site family consists of a large number of protein ligands that regulate diverse processes of embryonic induction and cell fate specification. Wnt signaling has been implied in the control of types of stem cells and considered as a niche factor to maintain the ability of self-renewal of stem cells. Wnt proteins, according to current understanding, bind to receptors of the Frizzled and LRP families on the cell surface (Nusse, 2008). These ligands and receptors are dynamically expressed to ensure the balance between stem cell proliferation and differentiation. Overexpression of Wnt-1 and Wnt-3a, as well as their signaling component, $\beta$-catenin, results in an increase in the number of cells undergoing mitosis in the ventricular zone of the spinal cord (Muroyama et al., 2004). The deletion of midbrain and the hippocampus in mice which are deficient for Wnt-1 and Wnt-3a also supports roles of Wnt genes in CNS development.

\section{Transcription factors}

The transcription factors such as Oct4, Sox2 and Nanog also play essential roles in early embryonic development and are required for the proliferation of undifferentiated ESCs in culture (Nichols et al., 1998; Avilion et al., 2003; Hart et al., 2004). They are found to control the pluripotency and self-renewal of hESCs. Oct4, Sox2 and Nanog co-occupy a substantial portion of their target genes, and collaborate to form regulatory paths including autoregulatory and feedforward loops (Boyer et al., 2005). Oct4, a member of the POU class of homeodomain proteins, is known to interact with other transcription factors, Sox2 for instance, to activate and repress gene expression in mouse embryonic cells (Botquin et al., 1998).

\section{Epigenetic regulation}

Epigenetic regulation, which involves in the entire development of the neural system, contributes to inheritable variations in gene expression or phenotype through DNA methylation, chromatin modifications, and non-coding RNA expression without changes in the DNA sequences.

\section{DNA methylation}

DNA methylation is an essential part of normal organismal development and cellular differentiation in higher organisms involving the addition of a methyl group $(-\mathrm{CH} 3)$ to the $5^{\prime}$ position of the pyrimidine ring of cytosine residues or the number 6 
nitrogen of the adenine purine ring by DNA methyltransferase (Dnmts) such as Dnmt3a and Dnmt3b (Goll and Bestor, 2005; Surani et al., 2007). DNA methylation, mainly occurring at CpG dinucleotides, modifies the gene expression pattern in cells and some of the modifications can be passed on through cell division. DNA methylation at the $5^{\prime}$ position of cytosine can specifically reduce gene expression by interfering with the association of transcription factors to their target gene sequence or through a family of methyl-CpG binding domain containing proteins (MBDs). DNA methylation contributes to the regulation of neural development. Loss of Dnmt3a in postnatal NS cells leads to the impairment of neurogenesis due to downregulation of neurogenic Dnmt3a target genes, such as, DIx2, Neurog2 and Sp8. In contrast, in Dnmt3a-null cultures, several Dnmt3a targets, like Sparcl1 and Nkx2-2, involved in astroglial and oligodendroglial differentiation were up-regulated ( $\mathrm{Wu}$ et al., 2010). DNA demethylation, on the other hand, has been illustrated to be essential for activity-dependent modulation of adult neurogenesis in the hippocampus regulated by an immediate early gene, Gadd45b (Ma et al., 2009).

\section{Chromatin modifications}

Variations of chromatin include covalent histone modification and non-covalent mechanism. Histone acetylation allows nuclear factors to gain an access to genetic locus, resulting in gene activation, while histone acetylation removed by histone deacetylases (HDACs) leads to gene repression (Kuo and Allis, 1998; Sterner and Berger, 2000). In general, an increase of histone acetylation by histone acetyltransferases (HATs) induces the remodeling of chromatin from a tightly packed configuration to a loose one, which facilitates transcriptional activation (Juliandi et al., 2010). Unlike histone acetylation, which is likely to be dynamic and reversible, histone methylation is more stable and usually could be reversed only by histone replacement.

\section{Non-coding RNA expression}

Non-protein coding RNAs (ncRNAs) have gained increasing attention by controlling many epigenetic phenomena recently. Several distinct classes of ncRNAs, microRNAs (miRNAs) have brought up fresh possibilities in terms of modulation of stem cells lineage commitment and differentiation. miRNA regulates gene expression by post-transcriptional inhibition or complementary mRNA sequence degradation (Ambros, 2003, 2004; He and Hannon, 2004). miRNAs targeting Nanog, Oct4, and Sox2 coding regions modulate ES cell differentiation (Tay et al., 2008). Generation of mature miR-26b, a microRNA encoded in an intron of the ctdsp2 primary transcript, is activated during neurogenesis, which suppresses expression of Ctdsp2 and is required for neuronal cell differentiation in vivo (Dill et al., 2012). miR-9 and miR-124 are miRNAs that are highly enriched in brain induced upon ES cells neuronal differentiation. Particularly, miR-124 is involved in the control of the lineage progression from adult SVZ transit-amplifying cells to neuroblasts (Cheng et al., 2009). In spite of a quite undetectable expression level during neurogenesis, miR-124 increasingly expresses during neuronal progenitor differentiation and eventually becomes the most abundant miRNA in the adult brain. This dramatic change in its expression level suggests a regulatory role of miR-124 in the transition progenitor to neuronal genes (Cheng et al., 2009).

Recently, a new class of large intergenic non-coding RNAs (lincRNAs) has been discovered, and they are direct targets of key pluripotency transcription factors, such as Oct4, Sox2 and Nanog. Overexpression of large intergenic non-coding RNAregulator of reprogramming (lincRNA-ROR) positively affects the establishment and maintenance of iPSCs during reprogramming (Loewer et al., 2010). lincRNAs are targets of ES cell transcription factors, and are able to affect gene expression in trans, maintain the pluripotent state, repress lineage programs, and bind to diverse chromatin proteins. Knockdown of a number of lincRNAs leads to either exit from the pluripotent state or upregulation of lineage commitment programs (Guttman et al., 2011).

\section{Surrounding cells}

NS cells differentiation is also affected by surrounding cells. Abundant evidence support the finding that NS cells differentiation is precisely regulated by the local environmental factors, such as glial cells, newborn neurons, and non-neuronal cells in the adult SVZ and SGZ. For example, NS cells are physically connected with endothelial cells. This association allows signaling molecules, such as the vascular endothelial growth factor (VEGF), to diffuse from endothelial into NS cells to promote neurogenesis. In addition, astrocytes can facilitate the differentiation of NS cells into neurons and the development of immature neurons by secreting neurotrophic factors (CorderoLlana et al., 2011).

\section{REPROGRAMMING OF SOMATIC SELLS INTO iPSCs AND DIFFERENTIATION OF IPSCs INTO NEURAL CELLS}

A pluripotent ESC being able to differentiate into all cell types has raised the issue of whether an ES cell-like pluripotent stem cell could be converted from one differentiated cell type. Strikingly, using ectopic co-expression of only four transcription factors: Oct3/4, Sox2, Klf4 and c-Myc (OSKM), Takahashi and Yamanaka have first announced the possibility of reprogramming mouse embryonic and adult fibroblasts into a new category of stem cells which are defined as induced pluripotent stem cells (iPSCs) (Takahashi and Yamanaka, 2006), and similar results have also been reported in human cells (Takahashi et al., 2007). In these four transcription factors, Oct3/4 has been proved to be the most important one because its expression is required for pluripotent stem cell generation (Niwa et al., 2000) and cannot be replaced by other Oct family members to generate iPSCs (Nakagawa et al., 2008). Kim et al. have generated iPSCs from adult mouse NS cells using Oct4 alone, which has demonstrated that Oct4 is sufficient to directly reprogram NS 
cells to be pluripotent (Kim et al., 2009). The first generation of iPSCs has the similar fundamental properties with embryonic stem cells, including comparable morphology, proliferation ability, surface antigens, expression of stem cell genes and telomerase activity. However, these cells failed to produce adult chimeric mice. Within a year, germline-competent iPSCs, that are capable of differentiating into cells of all three germ layers in teratomas and developing into viable chimeric mice, have been generated from mouse fibroblasts (Okita et al., 2007; Wernig et al., 2007). The tetraploid complementation approach further confirmed that iPSCs attain true pluripotency that is similar to that of ESCs (Kang et al., 2009; Zhao et al., 2009). In addition to fibroblasts, iPSCs could be generated from other somatic cells. For example, some studies have described the generation of mouse iPSCs from hepatocytes and gastric epithelial cells (Aoi et al., 2008), pancreatic $\beta$ cells (Stadtfeld et al., 2008a), neural stem cells (Kim et al., 2008; Silva et al., 2008) and B lymphocytes (Hanna et al., 2008). While human iPSCs could be generated from keratinocytes (Aasen et al., 2008) and blood progenitor cells (Loh et al., 2009).

Mechanistic studies of neurodegenerative diseases are generally based on autopsy samples or rodent models nowadays. The former approaches are limited in supply and only reveal endpoints of these diseases, while the latter methods do not fully recapitulate the disease pathogenesis. In theory, iPSCs are suitable tools for basic research and medical applications, including disease modeling, autologous cell therapy and drug or toxicity screening. The recent development of iPSCs opens an avenue to create live, patient-specific models of disease and to investigate monogenic and complex disease in vitro (Marchetto et al., 2010b; Zhu et al., 2011). For example, iPSC technology has the feasibility of capturing the genomes of Alzheimer's disease (AD) patients and generating cellular models of both the familial $A D(f A D)$ and sporadic $A D(S A D)$. The main strategy of iPSCs technology is that: first, take a small tissue biopsy, such as skin, from a patient; then, expand the biopsy into primary fibroblasts; finally, transduce the cells with retroviruses that encode the four transcription factors. After these processes, these cells are patientspecific stem cell lines that can theoretically differentiate into patientspecific neurons and glia in human body (Israel and Goldstein, 2011).

Most iPSCs are generated by using either retroviruses or lentiviruses carrying transgenes, which integrate into the host cell genome. During iPSCs generation, transgenes are largely silenced, while the reactivation of these transgenes, such as C-Myc, could result in tumor formation (Okita et al., 2007). Therefore, generating iPSCs without viral transfection show great advantages. To our interests, some studies have shown the possibility of inducing iPSCs without viral integration (Gonzalez et al., 2011). Stadtfeld et al. generated mouse iPSCs from fibroblasts and hepatocytes by using nonintegrating adenoviruses carrying the four reprogramming factors (Stadtfeld et al., 2008b). In another study, Okita et al. have generated the iPSCs without integration of transfected genes from mouse embryonic fibroblasts by repeated transfection of two expression plasmids that one expresses Oct3/4, Sox2, Klf4, the other expresses c-Myc, resulting in production of teratomas when transplanted into mice and development of adult chimeras (Okita et al., 2008; Okita et al., 2010). Another way to avoid integration of exogenous genes into donor cells is to deliver the reprogramming factors as proteins. Zhou et al. have generated iPSC colonies by delivery of recombinant OSKM proteins fused with a poly-arginine transduction domain (Zhao et al., 2009; Zhou et al., 2009). Recently, Warren et al. have developed a system that achieves the efficient conversion of different human somatic donor cells into iPSC using direct delivery of synthetic mRNAs (Warren et al., 2010). Although the non-integrative approaches might be more beneficial for iPSCs transplantation, many of these methods are extremely low and poorly reproducible or still represent oncogenetic risks.

To examine whether iPSCs could differentiate into neurons by using methods applied to hESCs, Takahashi et al. have seeded human IPSCs on PA6 feeder layer and maintained them under differentiation conditions for 2 weeks. Cells spread drastically, and neuron-like outgrowths are observed. These results have demonstrated that iPSCs could differentiate into neuronal cells (Takahashi et al., 2007). In another landmark study, Wernig et al. have cultured neural precursor cells derived from iPSCs. Upon transplantation into the fetal mouse brain, these neural progenitor cells migrate into various brain regions and differentiate into glia and neurons (Wernig et al., 2008). Furthermore, they have shown that iPSCs could be efficiently differentiated into dopamine neurons and able to improve the behavior of a rat model of Parkinson's disease upon transplantation into the adult brain. The exciting application of iPSC technology is predicated upon the potential to treat neurological disease with derivatives of patient-specific stem cells. In 2009, Karumbayaram et al. first demonstrated that human iPS-derived cells could differentiate into electrically active motor neurons, providing a method in regenerative medicine application and modeling of motor neuron diseases (Karumbayaram et al., 2009). By using Rett syndrome (RTT) as an Autism Spectrum Disorders (ASD) genetic model, Marchetto et al. have reported the differentiation of iPSC-derived embryoid bodies (EBs) in vitro into neuronal cultures (Fig. 1) that contained glutamatergic synapses which were capable of generating spontaneous synaptic activity (Marchetto et al., 2010a).

\section{DIRECT CONVERSION OF FIBROBLASTS TO NEURONS}

A potential disadvantage of iPSCs is the risk to form teratomas. If we could generate neural stem cells directly from fibroblasts or other types of somatic cells, it might eliminate the necessity of generating iPSCs and therefore would remove the risk of teratoma formation.

Recent studies have reported the directed conversion of rodent embryonic and postnatal fibroblasts to functional neurons, identifying a combination of three transcription factorsAscl1, Brn2 (also called Pou3f2) and Myt1l-and apparently 


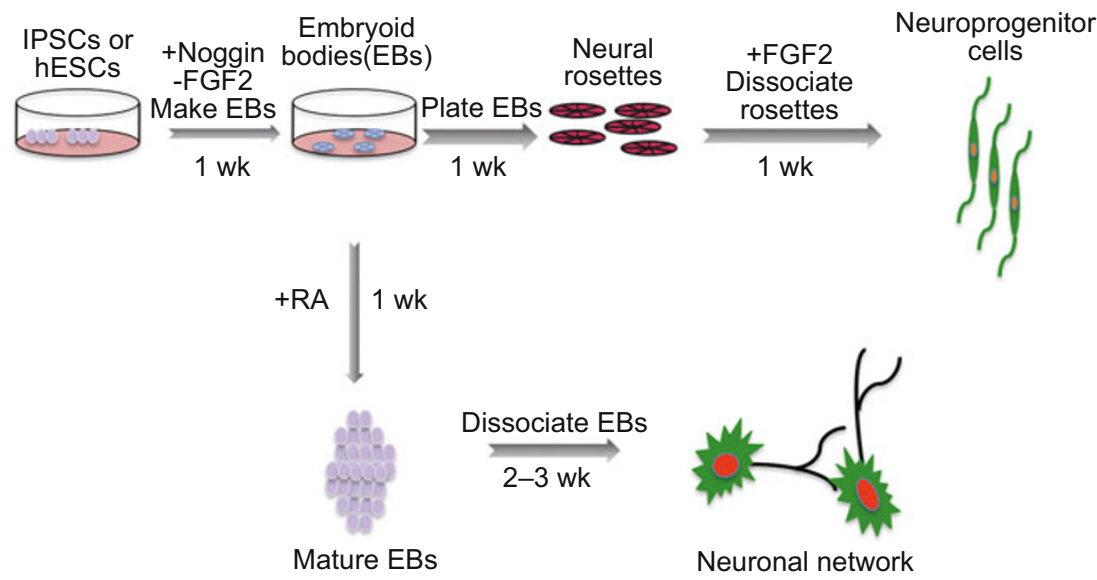

Figure 1. Schematic view of the neural differentiation protocol.

avoiding the production of a pluripotent intermediate state, which is associated with tumorigenesis and genetic instability (Vierbuchen et al., 2010). Using the same strategy, Pfisterer et al. subsequently demonstrated that overexpression of Ascl1, Brn2, and Myt1l could efficiently reprogram human fibroblasts to functional neurons. By co-expressing Lmx1a and FoxA2, which involved in dopamine neuron generation, they direct the phenotype of the converted cells toward dopaminergic neurons (Pfisterer et al., 2011). Another study has observed that NeuroD1, a basic helix-loop-helix transcription factor, could improve the efficiency of generating Tuj1-positive neuronal cells two to three folds after 3 weeks, when co-expressing with these three factors (Pang et al., 2011). These neurons could be matured to receive synaptic contacts, but on account of the facts that patient fibroblasts are much more exhaustible than iPSCs, thus, the application of this method on the study of AD would encounter some obstacles. At the same time, Caiazzo et al. has reported that another set of three transcription factorsMash1 (also known as Ascl1), Nurr1 (also known as Nr4a2) and Lmx1a-are sufficient to cause direct functional dopaminergic neuronal conversion in prenatal and adult fibroblasts from healthy donors and Parkinson's disease patients (Caiazzo et al., 2011). In addition to the known specific transcription factors that play critical roles in neuronal lineage determination, microRNAs also participate in the conversion of cell lineage. Ambasudhan et al. have showed that a combination of a microRNA (miR-124) and two transcription factors (MYT1L and BRN2) are able to directly elicit functional neuronal (ectoderm) conversion in postnatal and adult human primary dermal fibroblasts (mesoderm) under precisely defined conditions (Ambasudhan et al., 2011). In addition to avoiding the risk of teratoma formation, the direct conversion from fibroblasts to neurons also possesses an advantage of clinical application in neurological disease modeling. As a proof, Qiang et al. have generated human-induced neuronal cells from skin fibroblasts of familial Alzheimer disease patients with presenilin mutations or unaffected individuals (Qiang et al., 2011). However, this technology is limited by the fact that induced neuronal cells (iNCs) are termi- nally differentiated and cannot self-renew. Most recently, it has been reported that the combination of three or more factors, even only one factor-Sox2, can reprogram mouse fibroblasts into induced neural stem (iNS) cells with self-renewing ability. Cloned iNS cells are able to differentiate into several types of mature neurons, as well as astrocytes and oligodendrocytes, suggesting its multipotency (Ring et al., 2012). Implanted iNS cells can survive and integrate in mouse brains, and unlike iP. SC-derived NS cells, do not generate tumors (Kim et al., 2011; Han et al., 2012; Lujan et al., 2012; Ring et al., 2012; Sheng et al., 2012; Thier et al., 2012), suggesting iNS cells could be an alternative method for regenerative medicine. In addition, other studies have also proved the conversion of adult cells into other cell types for tissue repair and regeneration. For example, differentiated pancreatic exocrine cells in adult mouse can reprograms into induce $\beta$-cells by expression of specific combination of three transcription factors ( $\mathrm{Ngn} 3, \mathrm{Pdx} 1$ and Mafa) (Zhou et al., 2008). Song et al. have reported that four transcription factors, GATA4, HAND2, MEF2C and TBX5, can cooperatively reprogram adult mouse cardiac fibroblasts into functional cardiac-like myocytes (Song et al., 2012).

\section{TRANSDIFFERENTIATION OF NS CELLS INTO OTHERS}

On one hand, NS cells can be induced by reprogramming in other somatic cell types; on the other hand, NS cells can also transdifferentiate into brain endothelial cells in the irradiated brains. The data obtained through an examining of the cerebral blood flow before and after the implantation of NS cells in the positron emission tomography (PET) have demonstrated that endothelial cells differentiated from NS cells could function well in restoring the cerebral blood flow (Joo et al., 2012).

Comparison of the advantages and challenges of harnessing the cellular reprogramming method for regenerative medicine

Although directed differentiation of pluripotent stem cells such 
as embryonic stem cells or tissue-specific stem cells may provide an inexhaustible reservoir of generation of neuronal subtypes (Wichterle et al., 2002), initiating a very attractive area for research to explore the fate choice of a pluripotent cell toward a particular descendant, to date, only a handful of neural subtypes have been produced by this method and many of the neuronal subtypes arisen from stem cells do not have completely refined, subtype-specific properties resembling their counterparts from CNS (Peljto and Wichterle, 2011). On the other hand, the research with hESCs has been controversial due to the political, religious and ethical issues about the use of human embryos, resulting in the limitation of using ESCs. Therefore, recent researches have turned to focusing on producing pluripotent cells derived directly from somatic cells, followed by differentiation to convert them into new cell types. Since Takahashi and Yamanaka groundbreakingly reported that adult skin cells can be induced into pluripotent stem cells in culture by the viral expression of four transcription facrors:Oct4, Sox2, Klf4 and c-Myc (Takahashi and Yamanaka, 2006), iPSC technology has brought about a turning point in the field of stem cells, and it has rapidly become the major method of choice for regenerative medicine, aiming at uncovering disease pathogenesis, human genetic disease modeling and new drug screening and toxicity tests, finally for cell transplantation therapies.

The iPSCs share many properties with ESCs, such as morphology, immortal proliferation and pluripotency, but they are not identical as they display differences in gene expression signatures (Chin et al., 2009) and epigenetic states such as DNA methylation patterns (Deng et al., 2009). The potential advantages of iPSCs include offering greater scalability and flexibility, and a single iPSC clone can differentiate into multiple cell types relevant to particular symptoms (Chambers and Studer, 2011). Moreover, accumulated evidence suggests that iPSC technology can be used for the establishment of diseaseand patient-specific iPSCs lines and the genetic correction of disease-causing mutations in different patient cells, including those from patients with Huntington's disease (Park et al., 2008), ALS (Dimos et al., 2008), Parkinson's disease (Park et al., 2008; Soldner et al., 2011), Spinal Muscular Atrophy (Ebert et al., 2009), Schizophrenia (Brennand et al., 2011), Alzheimer's disease (Israel et al., 2012) and Hutchinson-Gilford progeria syndrome (Liu et al., 2011a). The corrected iPSCs are capable of rescuing mutant phenotypes in cultured cells (Liu et al., 2011b; Soldner et al., 2011; Yusa et al., 2011) or in mouse models of human diseases, such as sickle cell anemia (Hanna et al., 2007). The ultimate goal of using iPSCs is for cell transplantation therapy to repair and/or replace diseased and damaged tissues. However, a potential disadvantage of using iPSCs is the necessity that iPSCs generation need to first remove nearly all epigenetic marks established in somatic cell, then the adult cells must be completely de-differentiated to an ESC-like state, and finally these pluripotent cells would be amplified, characterized and re-differentiated into desired adult cell types. Thus, the process is a relatively complicated, time- consuming and inefficient detour. On the other hand, pluripotent stem cells, including ESCs and iPSCs, have nearly unlimited proliferative capacity in culture. Thus they can perform many cycles of proliferation to ensure their subsequent differentiation. iPSCs and ESCs could have a higher propensity to generate selectively fast-growing, culture-adapted cells that harbor subtle genetic mutation, which could lead to unstable phenotype, forming immature teratomas when these cells are transplanted in vivo. In fact, the patient-specific iPSC approach to study pathogenesis for human diseases also faces higher challenges. The differentiated cells derived from iPSCs in cell culture dish are difficult or impractical to model late-onset human diseases such as Alzheimer's or Parkinson's diseases as the pathogenesis of these diseases is a long latency process and combination of genetic and environmental factors including interactions of the different cell types, physiological cue and epigenetic alterations affected by disease (Saha and Jaenisch, 2009). In addition, iPSCs also show other weaknesses such as incomplete reprogramming, tissue inappropriate differentiation, or insertional mutagenesis caused by the reprogramming factors that is indeed a serious concern for clinical translation.

Strikingly, recent advances in lineage reprogramming or direct reprogramming provide a more direct route to convert one differentiated cell type like fibroblasts into specific neuronal subtype through the ectopic expression of defined combination of transcription factors. Importantly, these induced neuronal cells are all indicative of neuron identities, including expressing multiple neuron-specific proteins, generating electrophysiological activity, forming functional synapses and in vivo engraftment capacity, sensitivity to disease stimuli (Vierbuchen et al., 2010; Son et al., 2011). Although iNCs can be generated with relatively high efficiency $(5 \%-20 \%)$, they fail to self-renew in culture and only a mixture of neuronal cells and other unknown types of cells can be generated by current protocols, limiting the direct use of iNCs in transplantation therapy. Most recently, Ring et al take a great stride to improve the efficiency of lineage reprogramming (Ring et al., 2012). They present a novel discovery of generating self-renewable, multipotent neural lineage-restricted, and non-tumorigenic iNS cells from mouse and human fibroblasts by direct reprogramming with one factor. These iNS cells can develop into subtype-specific neurons, which would complement the iPSC and iNC technologies and sidestep their shortcomings. These findings reveal a new tool for mechanistic studies, drug screening, and potential cell therapies for different neurodegenerative diseases.

In contrast to iPSCs, lineage reprogramming process based on transdifferentiation and dedifferentiation requires shorter time, and simpler differentiation condition for conversion cell types. The lineage reprogramming process only takes one step back to produce differentiated cell lineage, and the process mostly occur between closely related cell types (Choi et al., 1990; Kondo and Raff, 2000; Xie et al., 2004; Cobaleda et al., 2007; Orkin and Zon, 2008), whereas the products of pluripotent reprogramming, iPSCs, remain dependent on further differentiation into tissue-specific progenitor or mature 
cells. Another potential advantage of lineage reprogramming is the possibility that directed differentiation may need fewer proliferation steps, which could reduce the chance of mutations and tumors occurrence. Thus, lineage reprogramming may promise the development of powerful in situ regeneration and repair strategies by in vivo converting cells directly, but not suitable for iPSCs-based reprogramming process. Currently, lineage reprogramming has received significant attention since it could serve as a complement for pluripotent reprogramming and iPSC technology, and could become a more effective approach and alternative strategy for regenerative medicine.

Every coin has two sides; lineage reprogramming also leaves many problems unsolved. For example, the first question is which type of the origin cells is the best one for reprogramming, and whether cell type conversion remain in distantly related cell lineages. The second challenge is to determine the minimum factors combination required for reprogramming. The third question is the efficiency of lineage reprogramming. How many corrected and reprogrammed cells can survive and integrate in vivo to respond to physiological cues? Comparing the intracellular state of the induced cells with their target cell counterparts, we raise another question about the alterations of cellular characteristics. Many experiments have demonstrated that iPSCs can maintain the pattern of pluripotent markers expression, differentiation potentiality, epigenetic state after complete removal of reprogramming factors (Hanna et al., 2010), but whether the maintenance of stable reprogrammed cell fate exists in differentiated cell types during directed reprogramming is still questionable. Finally, the most critical challenge is related to translational medicine application. The primary goal of regenerative medicine is to translate research achievements to the clinic therapy. How does the lineage reprogramming assure sufficient functionality of induced cell subtypes in therapeutic applications without increasing the risk of tumor formation or other abnormal cell behaviors? For future translational applications, it is especially important to consider the advantages and disadvantages of lineage reprogramming by comparison with the use of iPSCs or ESCs-derived cell types.

\section{CONCLUSIONS AND PERSPECTIVE}

The technology of somatic cell reprogramming has opened up a vast new territory in searching for effective treatments for human diseases, including neurological diseases. iPSCs have the capacity to generate diverse viable progenies, facilitating the therapeutic application research of iPSCs in regenerative medicine. Cell differentiation methods by direct reprogramming through the ectopic expression of defined factors also offer an attractive strategy with distinct advantages to become an important complement for iPSCs technology. However, the use of iPSCs and/or direct reprogramming cells requires overcoming many challenges discussed above. For now, the greatest challenge facing effective cellular reprogramming is to ensure clinical effect and safety. It is extremely essential for reprogramming technology to generate a large number of viable and homogenous differentiated cell populations, which are of human origin, and retain their phenotypes, functionalities and cell behaviors meanwhile to eliminate tumor formation potency after transplantation. Despite of many challenges and drawbacks of the reprogramming approach laying ahead, we are still optimistic that the cellular therapies based on induced pluripotency and/or lineage reprogramming have the great potential for curing human disorders in future.

\section{ACKNOWLEDGEMENTS}

This work is supported by the National Basic Research Program 973 program (No. 2012CB966800), the Thousand Youth Talents Program and the Pioneer Programs of Chinese Academy of Sciences.

\section{ABBREVIATIONS}

AD, Alzheimer's disease; ALS, Amyotrophic Lateral Sclerosis; BMP, bone morphogenetic protein; CNS, central nervous system; EB, embryoid body; fAD, familial AD; HAT, histone acetyltransferase; HD, Huntington's disease; HDAC, histone deacetylase; hESC, human embryonic stem cell; HPE, holoprosencephaly; IPSC, induced pluripotent stem cell; lincRNA, intergenic non-coding RNA; MBD, methyl-CpG binding domain containing protein; MEF, mouse embryonic fibroblast; miRNA, microRNA; ncRNA, non-protein coding RNA; NS, neural stem; $\mathrm{PET}$, positron emission tomograph; PD, Parkinson's disease; ROR, regulator of reprogramming; $S A D$, sporadic $A D$; $S G Z$, subgranular zone; Shh, sonic hedgehog; SMA, Spinal Muscular Atrophy; SVZ, subventricular zone; TGF $\beta$, transforming growth factor $\beta$; VEGF, vascular endothelial growth factor

\section{REFERENCES}

Aasen, T., Raya, A., Barrero, M.J., Garreta, E., Consiglio, A., Gonzalez, F., Vassena, R., Bilic, J., Pekarik, V., Tiscornia, G., et al. (2008). Efficient and rapid generation of induced pluripotent stem cells from human keratinocytes. Nat Biotechnol 26, 1276-1284.

Altman, J., and Das, G.D. (1965). Autoradiographic and histological evidence of postnatal hippocampal neurogenesis in rats. J Comp Neurol 124, 319-335.

Ambasudhan, R., Talantova, M., Coleman, R., Yuan, X., Zhu, S., Lipton, S.A., and Ding, S. (2011). Direct reprogramming of adult human fibroblasts to functional neurons under defined conditions. Cell Stem Cell 9, 113-118.

Ambros, V. (2003). MicroRNA pathways in flies and worms: growth, death, fat, stress, and timing. Cell 113, 673-676.

Ambros, V. (2004). The functions of animal microRNAs. Nature 431, 350-355.

Aoi, T., Yae, K., Nakagawa, M., Ichisaka, T., Okita, K., Takahashi, K., Chiba, T., and Yamanaka, S. (2008). Generation of pluripotent stem cells from adult mouse liver and stomach cells. Science 321 , 699-702.

Attisano, L., and Wrana, J.L. (2002). Signal transduction by the TGFbeta superfamily. Science 296, 1646-1647.

Avilion, A.A., Nicolis, S.K., Pevny, L.H., Perez, L., Vivian, N., and Lovell-Badge, R. (2003). Multipotent cell lineages in early mouse development depend on SOX2 function. Genes \& development 17 , 126-140.

Botquin, V., Hess, H., Fuhrmann, G., Anastassiadis, C., Gross, M.K., Vriend, G., and Scholer, H.R. (1998). New POU dimer configuration 
mediates antagonistic control of an osteopontin preimplantation enhancer by Oct-4 and Sox-2. Genes \& development 12, 2073-2090.

Boulting, G.L., Kiskinis, E., Croft, G.F., Amoroso, M.W., Oakley, D.H., Wainger, B.J., Williams, D.J., Kahler, D.J., Yamaki, M., Davidow, L., et al. (2011). A functionally characterized test set of human induced pluripotent stem cells. Nat Biotechnol 29, 279-286.

Boyer, L.A., Lee, T.I., Cole, M.F., Johnstone, S.E., Levine, S.S., Zucker, J.P., Guenther, M.G., Kumar, R.M., Murray, H.L., Jenner, R.G., et al. (2005). Core transcriptional regulatory circuitry in human embryonic stem cells. Cell 122, 947-956.

Brennand, K.J., Simone, A., Jou, J., Gelboin-Burkhart, C., Tran, N., Sangar, S., Li, Y., Mu, Y., Chen, G., Yu, D., et al. (2011). Modelling schizophrenia using human induced pluripotent stem cells. Nature 473, 221-225.

Caiazzo, M., Dell'Anno, M.T., Dvoretskova, E., Lazarevic, D., Taverna, S., Leo, D., Sotnikova, T.D., Menegon, A., Roncaglia, P., Colciago, G., et al. (2011). Direct generation of functional dopaminergic neurons from mouse and human fibroblasts. Nature 476, 224-227.

Chambers, S.M., and Studer, L. (2011). Cell fate plug and play: direct reprogramming and induced pluripotency. Cell 145, 827-830.

Chen, J., Liu, J., Yang, J., Chen, Y., Ni, S., Song, H., Zeng, L., Ding, K., and Pei, D. (2011). BMPs functionally replace Klf4 and support efficient reprogramming of mouse fibroblasts by Oct4 alone. Cell Res 21, 205-212.

Cheng, L.C., Pastrana, E., Tavazoie, M., and Doetsch, F. (2009). miR124 regulates adult neurogenesis in the subventricular zone stem cell niche. Nat Neurosci 12, 399-408.

Chin, M.H., Mason, M.J., Xie, W., Volinia, S., Singer, M., Peterson, C., Ambartsumyan, G., Aimiuwu, O., Richter, L., Zhang, J., et al. (2009). Induced pluripotent stem cells and embryonic stem cells are distinguished by gene expression signatures. Cell Stem Cell 5, 111-123.

Choi, J., Costa, M.L., Mermelstein, C.S., Chagas, C., Holtzer, S., and Holtzer, H. (1990). MyoD converts primary dermal fibroblasts, chondroblasts, smooth muscle, and retinal pigmented epithelial cells into striated mononucleated myoblasts and multinucleated myotubes. Proc Natl Acad Sci U S A 87, 7988-7992.

Cobaleda, C., Jochum, W., and Busslinger, M. (2007). Conversion of mature $B$ cells into $T$ cells by dedifferentiation to uncommitted progenitors. Nature 449, 473-477.

Cordero-Llana, O., Scott, S.A., Maslen, S.L., Anderson, J.M., Boyle, J., Chowhdury, R.R., Tyers, P., Barker, R.A., Kelly, C.M., Rosser, A.E., et al. (2011). Clusterin secreted by astrocytes enhances neuronal differentiation from human neural precursor cells. Cell Death Differ 18, 907-913.

Deng, J., Shoemaker, R., Xie, B., Gore, A., LeProust, E.M., Antosiewicz-Bourget, J., Egli, D., Maherali, N., Park, I.H., Yu, J., et al. (2009). Targeted bisulfite sequencing reveals changes in DNA methylation associated with nuclear reprogramming. Nat Biotechnol 27, 353-360.

Denham, M., and Dottori, M. (2009). Signals involved in neural differentiation of human embryonic stem cells. Neurosignals 17 , 234-241.

Dessaud, E., McMahon, A.P., and Briscoe, J. (2008). Pattern formation in the vertebrate neural tube: a sonic hedgehog morphogenregulated transcriptional network. Development 135, 2489-2503.

Dhara, S.K., and Stice, S.L. (2008). Neural differentiation of human embryonic stem cells. J Cell Biochem 105, 633-640.
Dill, H., Linder, B., Fehr, A., and Fischer, U. (2012). Intronic miR-26b controls neuronal differentiation by repressing its host transcript, ctdsp2. Genes Dev 26, 25-30.

Dimos, J.T., Rodolfa, K.T., Niakan, K.K., Weisenthal, L.M., Mitsumoto, H., Chung, W., Croft, G.F., Saphier, G., Leibel, R., Goland, R., et al. (2008). Induced pluripotent stem cells generated from patients with ALS can be differentiated into motor neurons. Science 321 , 1218-1221.

Ebert, A.D., Yu, J., Rose, F.F., Jr., Mattis, V.B., Lorson, C.L., Thomson, J.A., and Svendsen, C.N. (2009). Induced pluripotent stem cells from a spinal muscular atrophy patient. Nature 457, 277-280.

Elkabetz, Y., and Studer, L. (2008). Human ESC-derived neural rosettes and neural stem cell progression. Cold Spring Harb Symp Quant Biol 73, 377-387.

Evans, M.J., and Kaufman, M.H. (1981). Establishment in culture of pluripotential cells from mouse embryos. Nature 292, 154-156.

Gaspard, N., and Vanderhaeghen, P. (2010). Mechanisms of neural specification from embryonic stem cells. Curr Opin Neurobiol 20, 37-43.

Goll, M.G., and Bestor, T.H. (2005). Eukaryotic cytosine methyltransferases. Annu Rev Biochem 74, 481-514.

Gonzalez, F., Boue, S., and Izpisua Belmonte, J.C. (2011). Methods for making induced pluripotent stem cells: reprogramming a la carte. Nat Rev Genet 12, 231-242.

Guttman, M., Donaghey, J., Carey, B.W., Garber, M., Grenier, J.K., Munson, G., Young, G., Lucas, A.B., Ach, R., Bruhn, L., et al. (2011). lincRNAs act in the circuitry controlling pluripotency and differentiation. Nature 477, 295-300.

Han, D.W., Tapia, N., Hermann, A., Hemmer, K., Hoing, S., ArauzoBravo, M.J., Zaehres, H., Wu, G., Frank, S., Moritz, S., et al. (2012). Direct reprogramming of fibroblasts into neural stem cells by defined factors. Cell Stem Cell 10, 465-472.

Hanna, J., Markoulaki, S., Schorderet, P., Carey, B.W., Beard, C., Wernig, M., Creyghton, M.P., Steine, E.J., Cassady, J.P., Foreman, $\mathrm{R}$., et al. (2008). Direct reprogramming of terminally differentiated mature B lymphocytes to pluripotency. Cell 133, 250-264.

Hanna, J., Wernig, M., Markoulaki, S., Sun, C.W., Meissner, A., Cassady, J.P., Beard, C., Brambrink, T., Wu, L.C., Townes, T.M., et al. (2007). Treatment of sickle cell anemia mouse model with iPS cells generated from autologous skin. Science 318, 1920-1923.

Hanna, J.H., Saha, K., and Jaenisch, R. (2010). Pluripotency and cellular reprogramming: facts, hypotheses, unresolved issues. Cell 143, 508-525.

Hart, A.H., Hartley, L., Ibrahim, M., and Robb, L. (2004). Identification, cloning and expression analysis of the pluripotency promoting Nanog genes in mouse and human. Developmental dynamics : an official publication of the American Association of Anatomists 230, 187-198.

He, L., and Hannon, G.J. (2004). MicroRNAs: small RNAs with a big role in gene regulation. Nat Rev Genet 5, 522-531.

Israel, M.A., and Goldstein, L.S. (2011). Capturing Alzheimer's disease genomes with induced pluripotent stem cells: prospects and challenges. Genome Med 3, 49.

Israel, M.A., Yuan, S.H., Bardy, C., Reyna, S.M., Mu, Y., Herrera, C., Hefferan, M.P., Van Gorp, S., Nazor, K.L., Boscolo, F.S., et al. (2012). Probing sporadic and familial Alzheimer's disease using induced pluripotent stem cells. Nature 482, 216-220.

Joo, K.M., Jin, J., Kang, B.G., Lee, S.J., Kim, K.H., Yang, H., Lee, Y.A., 
Cho, Y.J., Im, Y.S., Lee, D.S., et al. (2012). Trans-differentiation of neural stem cells: a therapeutic mechanism against the radiation induced brain damage. PLoS One 7, e25936.

Juliandi, B., Abematsu, M., and Nakashima, K. (2010). Chromatin remodeling in neural stem cell differentiation. Curr Opin Neurobiol 20, 408-415.

Kang, L., Wang, J., Zhang, Y., Kou, Z., and Gao, S. (2009). iPS cells can support full-term development of tetraploid blastocyst-complemented embryos. Cell Stem Cell 5, 135-138.

Karumbayaram, S., Novitch, B.G., Patterson, M., Umbach, J.A., Richter, L., Lindgren, A., Conway, A.E., Clark, A.T., Goldman, S.A., Plath, K., et al. (2009). Directed differentiation of human-induced pluripotent stem cells generates active motor neurons. Stem Cells 27, 806-811.

Kim, J., Efe, J.A., Zhu, S., Talantova, M., Yuan, X., Wang, S., Lipton, S.A., Zhang, K., and Ding, S. (2011). Direct reprogramming of mouse fibroblasts to neural progenitors. Proc Natl Acad Sci U S A 108, 7838-7843.

Kim, J.B., Sebastiano, V., Wu, G., Arauzo-Bravo, M.J., Sasse, P., Gentile, L., Ko, K., Ruau, D., Ehrich, M., van den Boom, D., et al. (2009). Oct4-induced pluripotency in adult neural stem cells. Cell 136, 411-419.

Kim, J.B., Zaehres, H., Wu, G., Gentile, L., Ko, K., Sebastiano, V., Arauzo-Bravo, M.J., Ruau, D., Han, D.W., Zenke, M., et al. (2008). Pluripotent stem cells induced from adult neural stem cells by reprogramming with two factors. Nature 454, 646-650.

Kim, P.C., Mo, R., and Hui Cc, C. (2001). Murine models of VACTERL syndrome: Role of sonic hedgehog signaling pathway. J Pediatr Surg 36, 381-384.

Kondo, T., and Raff, M. (2000). Oligodendrocyte precursor cells reprogrammed to become multipotential CNS stem cells. Science 289, 1754-1757.

Kuo, M.H., and Allis, C.D. (1998). Roles of histone acetyltransferases and deacetylases in gene regulation. Bioessays 20, 615-626.

Lee, J., Platt, K.A., Censullo, P., and Ruiz i Altaba, A. (1997). Gli1 is a target of Sonic hedgehog that induces ventral neural tube development. Development 124, 2537-2552.

Liu, G.H., Barkho, B.Z., Ruiz, S., Diep, D., Qu, J., Yang, S.L., Panopoulos, A.D., Suzuki, K., Kurian, L., Walsh, C., et al. (2011a). Recapitulation of premature ageing with iPSCs from Hutchinson-Gilford progeria syndrome. Nature 472, 221-225.

Liu, G.H., Suzuki, K., Qu, J., Sancho-Martinez, I., Yi, F., Li, M., Kumar, S., Nivet, E., Kim, J., Soligalla, R.D., et al. (2011b). Targeted gene correction of laminopathy-associated LMNA mutations in patientspecific iPSCs. Cell Stem Cell 8, 688-694.

Loewer, S., Cabili, M.N., Guttman, M., Loh, Y.H., Thomas, K., Park, I.H., Garber, M., Curran, M., Onder, T., Agarwal, S., et al. (2010). Large intergenic non-coding RNA-RoR modulates reprogramming of human induced pluripotent stem cells. Nat Genet 42, 1113-1117.

Loh, Y.H., Agarwal, S., Park, I.H., Urbach, A., Huo, H., Heffner, G.C., Kim, K., Miller, J.D., Ng, K., and Daley, G.Q. (2009). Generation of induced pluripotent stem cells from human blood. Blood 113, 5476-5479.

Lujan, E., Chanda, S., Ahlenius, H., Sudhof, T.C., and Wernig, M. (2012). Direct conversion of mouse fibroblasts to self-renewing, tripotent neural precursor cells. Proc Natl Acad Sci U S A 109, 2527-2532.
Ma, D.K., Jang, M.H., Guo, J.U., Kitabatake, Y., Chang, M.L., PowAnpongkul, N., Flavell, R.A., Lu, B., Ming, G.L., and Song, H. (2009). Neuronal activity-induced Gadd45b promotes epigenetic DNA demethylation and adult neurogenesis. Science 323, 1074-1077.

Marchetto, M.C., Carromeu, C., Acab, A., Yu, D., Yeo, G.W., Mu, Y., Chen, G., Gage, F.H., and Muotri, A.R. (2010a). A model for neural development and treatment of Rett syndrome using human induced pluripotent stem cells. Cell 143, 527-539.

Marchetto, M.C., Winner, B., and Gage, F.H. (2010b). Pluripotent stem cells in neurodegenerative and neurodevelopmental diseases. Hum Mol Genet 19, R71-76.

Marti, E., Takada, R., Bumcrot, D.A., Sasaki, H., and McMahon, A.P. (1995). Distribution of Sonic hedgehog peptides in the developing chick and mouse embryo. Development 121, 2537-2547.

Mullor, J.L., Sanchez, P., and Ruiz i Altaba, A. (2002). Pathways and consequences: Hedgehog signaling in human disease. Trends Cell Biol 12, 562-569.

Muroyama, Y., Kondoh, H., and Takada, S. (2004). Wnt proteins promote neuronal differentiation in neural stem cell culture. Biochem Biophys Res Commun 313, 915-921.

Nakagawa, M., Koyanagi, M., Tanabe, K., Takahashi, K., Ichisaka, T., Aoi, T., Okita, K., Mochiduki, Y., Takizawa, N., and Yamanaka, S. (2008). Generation of induced pluripotent stem cells without Myc from mouse and human fibroblasts. Nat Biotechnol 26, 101-106.

Nichols, J., Zevnik, B., Anastassiadis, K., Niwa, H., Klewe-Nebenius, D., Chambers, I., Scholer, H., and Smith, A. (1998). Formation of pluripotent stem cells in the mammalian embryo depends on the POU transcription factor Oct4. Cell 95, 379-391.

Niwa, H., Miyazaki, J., and Smith, A.G. (2000). Quantitative expression of Oct-3/4 defines differentiation, dedifferentiation or self-renewal of ES cells. Nat Genet 24, 372-376.

Nusse, R. (2008). Wht signaling and stem cell control. Cell Res 18, 523-527.

Okita, K., Hong, H., Takahashi, K., and Yamanaka, S. (2010). Generation of mouse-induced pluripotent stem cells with plasmid vectors. Nat Protoc 5, 418-428.

Okita, K., Ichisaka, T., and Yamanaka, S. (2007). Generation of germline-competent induced pluripotent stem cells. Nature 448 , 313-317.

Okita, K., Nakagawa, M., Hong, H.J., Ichisaka, T., and Yamanaka, S. (2008). Generation of mouse induced pluripotent stem cells without viral vectors. Science 322, 949-953.

Orkin, S.H., and Zon, L.I. (2008). Hematopoiesis: an evolving paradigm for stem cell biology. Cell 132, 631-644.

Pang, Z.P., Yang, N., Vierbuchen, T., Ostermeier, A., Fuentes, D.R., Yang, T.Q., Citri, A., Sebastiano, V., Marro, S., Sudhof, T.C., et al. (2011). Induction of human neuronal cells by defined transcription factors. Nature 476, 220-223.

Park, I.H., Arora, N., Huo, H., Maherali, N., Ahfeldt, T., Shimamura, A., Lensch, M.W., Cowan, C., Hochedlinger, K., and Daley, G.Q. (2008). Disease-specific induced pluripotent stem cells. Cell 134, 877-886.

Peljto, M., and Wichterle, H. (2011). Programming embryonic stem cells to neuronal subtypes. Curr Opin Neurobiol 21, 43-51.

Pfisterer, U., Kirkeby, A., Torper, O., Wood, J., Nelander, J., Dufour, A., Bjorklund, A., Lindvall, O., Jakobsson, J., and Parmar, M. (2011). Direct conversion of human fibroblasts to dopaminergic neurons. Proc Natl Acad Sci U S A 108, 10343-10348. 
Qiang, L., Fujita, R., Yamashita, T., Angulo, S., Rhinn, H., Rhee, D., Doege, C., Chau, L., Aubry, L., Vanti, W.B., et al. (2011). Directed conversion of Alzheimer's disease patient skin fibroblasts into functional neurons. Cell 146, 359-371.

Ring, K.L., Tong, L.M., Balestra, M.E., Javier, R., Andrews-Zwilling, Y., Li, G., Walker, D., Zhang, W.R., Kreitzer, A.C., and Huang, Y. (2012). Direct reprogramming of mouse and human fibroblasts into multipotent neural stem cells with a single factor. Cell Stem Cell 11, 100-109.

Saha, K., and Jaenisch, R. (2009). Technical challenges in using human induced pluripotent stem cells to model disease. Cell Stem Cell 5, 584-595.

Sheng, C., Zheng, Q., Wu, J., Xu, Z., Wang, L., Li, W., Zhang, H., Zhao, X.Y., Liu, L., Wang, Z., et al. (2012). Direct reprogramming of Sertoli cells into multipotent neural stem cells by defined factors. Cell Res 22, 208-218.

Silva, J., Barrandon, O., Nichols, J., Kawaguchi, J., Theunissen, T.W., and Smith, A. (2008). Promotion of reprogramming to ground state pluripotency by signal inhibition. PLoS Biol 6, e253.

Soldner, F., Laganiere, J., Cheng, A.W., Hockemeyer, D., Gao, Q., Alagappan, R., Khurana, V., Golbe, L.I., Myers, R.H., Lindquist, S., et al. (2011). Generation of isogenic pluripotent stem cells differing exclusively at two early onset Parkinson point mutations. Cell 146, 318-331.

Son, E.Y., Ichida, J.K., Wainger, B.J., Toma, J.S., Rafuse, V.F., Woolf, C.J., and Eggan, K. (2011). Conversion of mouse and human fibroblasts into functional spinal motor neurons. Cell Stem Cell 9, 205-218.

Song, K., Nam, Y.J., Luo, X., Qi, X., Tan, W., Huang, G.N., Acharya, A., Smith, C.L., Tallquist, M.D., Neilson, E.G., et al. (2012). Heart repair by reprogramming non-myocytes with cardiac transcription factors. Nature 485, 599-604.

Stadtfeld, M., Brennand, K., and Hochedlinger, K. (2008a). Reprogramming of pancreatic beta cells into induced pluripotent stem cells. Curr Biol 18, 890-894.

Stadtfeld, M., Nagaya, M., Utikal, J., Weir, G., and Hochedlinger, K. (2008b). Induced pluripotent stem cells generated without viral integration. Science 322, 945-949.

Sterner, D.E., and Berger, S.L. (2000). Acetylation of histones and transcription-related factors. Microbiol Mol Biol Rev 64, 435-459.

Surani, M.A., Hayashi, K., and Hajkova, P. (2007). Genetic and epigenetic regulators of pluripotency. Cell 128, 747-762.

Tabata, T., and Takei, Y. (2004). Morphogens, their identification and regulation. Development 131, 703-712.

Takahashi, K., Tanabe, K., Ohnuki, M., Narita, M., Ichisaka, T., Tomoda, K., and Yamanaka, S. (2007). Induction of pluripotent stem cells from adult human fibroblasts by defined factors. Cell 131, 861-872.

Takahashi, K., and Yamanaka, S. (2006). Induction of pluripotent stem cells from mouse embryonic and adult fibroblast cultures by defined factors. Cell 126, 663-676.

Tay, Y., Zhang, J., Thomson, A.M., Lim, B., and Rigoutsos, I. (2008). MicroRNAs to Nanog, Oct4 and Sox2 coding regions modulate embryonic stem cell differentiation. Nature 455, 1124-1128.

Thier, M., Worsdorfer, P., Lakes, Y.B., Gorris, R., Herms, S., Opitz, T., Seiferling, D., Quandel, T., Hoffmann, P., Nothen, M.M., et al. (2012). Direct Conversion of Fibroblasts into Stably Expandable Neural
Stem Cells. Cell Stem Cell 10, 473-479.

Thomson, J.A. (1998). Embryonic Stem Cell Lines Derived from Human Blastocysts. Science 282, 1145-1147.

Varga, A.C., and Wrana, J.L. (2005). The disparate role of BMP in stem cell biology. Oncogene 24, 5713-5721.

Vierbuchen, T., Ostermeier, A., Pang, Z.P., Kokubu, Y., Sudhof, T.C., and Wernig, M. (2010). Direct conversion of fibroblasts to functional neurons by defined factors. Nature 463, 1035-1041.

Wang, B., Fallon, J.F., and Beachy, P.A. (2000). Hedgehog-regulated processing of Gli3 produces an anterior/posterior repressor gradient in the developing vertebrate limb. Cell 100, 423-434.

Warren, L., Manos, P.D., Ahfeldt, T., Loh, Y.H., Li, H., Lau, F., Ebina, W., Mandal, P.K., Smith, Z.D., Meissner, A., et al. (2010). Highly efficient reprogramming to pluripotency and directed differentiation of human cells with synthetic modified mRNA. Cell Stem Cell 7, 618-630.

Wernig, M., Meissner, A., Foreman, R., Brambrink, T., Ku, M., Hochedlinger, K., Bernstein, B.E., and Jaenisch, R. (2007). In vitro reprogramming of fibroblasts into a pluripotent ES-cell-like state. Nature 448, 318-324.

Wernig, M., Zhao, J.P., Pruszak, J., Hedlund, E., Fu, D., Soldner, F., Broccoli, V., Constantine-Paton, M., Isacson, O., and Jaenisch, R. (2008). Neurons derived from reprogrammed fibroblasts functionally integrate into the fetal brain and improve symptoms of rats with Parkinson's disease. Proc Natl Acad Sci U S A 105, 5856-5861.

Wichterle, H., Lieberam, I., Porter, J.A., and Jessell, T.M. (2002). Directed differentiation of embryonic stem cells into motor neurons. Cell 110, 385-397.

Wu, H., Coskun, V., Tao, J., Xie, W., Ge, W., Yoshikawa, K., Li, E., Zhang, Y., and Sun, Y.E. (2010). Dnmt3a-dependent nonpromoter DNA methylation facilitates transcription of neurogenic genes. Science 329, 444-448.

Xie, H., Ye, M., Feng, R., and Graf, T. (2004). Stepwise reprogramming of B cells into macrophages. Cell 117, 663-676.

Yao, J., Mu, Y., and Gage, F.H. (2012). Neural stem cells: mechanisms and modeling. Protein Cell 3, 251-261.

Yusa, K., Rashid, S.T., Strick-Marchand, H., Varela, I., Liu, P.Q., Paschon, D.E., Miranda, E., Ordonez, A., Hannan, N.R., Rouhani, F.J., et al. (2011). Targeted gene correction of alpha1-antitrypsin deficiency in induced pluripotent stem cells. Nature 478, 391-394.

Zhang, S.C. (2006). Neural subtype specification from embryonic stem cells. Brain Pathol 16, 132-142.

Zhao, X.Y., Li, W., Lv, Z., Liu, L., Tong, M., Hai, T., Hao, J., Guo, C.L., Ma, Q.W., Wang, L., et al. (2009). iPS cells produce viable mice through tetraploid complementation. Nature 461, 86-90.

Zhou, H., Wu, S., Joo, J.Y., Zhu, S., Han, D.W., Lin, T., Trauger, S., Bien, G., Yao, S., Zhu, Y., et al. (2009). Generation of induced pluripotent stem cells using recombinant proteins. Cell Stem Cell 4 , 381-384.

Zhou, Q., Brown, J., Kanarek, A., Rajagopal, J., and Melton, D.A. (2008). In vivo reprogramming of adult pancreatic exocrine cells to beta-cells. Nature 455, 627-632.

Zhu, H., Lensch, M.W., Cahan, P., and Daley, G.Q. (2011). Investigating monogenic and complex diseases with pluripotent stem cells. Nat Rev Genet 12, 266-275. 